\title{
Research on the tensile mechanics properties of steel fiber RPC
}

\author{
YUAN Haiyan ${ }^{1, a}$, AN Mingzhe ${ }^{2, b}$, YU Ziruo ${ }^{2, c}, \quad$ ZHU Chunmei ${ }^{1, d}$
}

1. School of Civil Engineering and Architecture, University of Jinan, Jinan 250022, China

2. School of Civil Engineering, Beijing Jiaotong University, Beijing 100044, China

acea_yuanhy@ujn.edu.cn, banmingzhe01@163.com, 'zryu@bjtu.edu.cn, 'cea_zhucm@ujn.edu.cn,

Keywords: reactive powder concrete; axial tensile strength; splitting tensile strength; flexural tensile strength.

Abstract. In order to study the tensile strength of reactive powder concrete (RPC) with different volume fraction of steel fiber $\left(V_{\mathrm{f}}=0 \%, 1 \%, 2 \%\right)$, the axial tensile tests were completed using self-designed equipment. The splitting tensile test and flexural tensile test were developed at the same time. The results indicated that the ratio of axial tensile strength and splitting tensile strength of RPC is descending as the steel fiber volumetric ratio increasing, but the ratio of axial tensile strength and flexural tensile strength is almost stabilized.

\section{Introduction}

Reactive Powder Concrete (RPC) is a new type of green concrete material. RPC possess excellent properties such as ultra-high static and dynamic strength, high tensile strength, high toughness and high durability, etc. [1, 2]. Those characteristics especially for tensile toughness make RPC a great potential prospect in civil engineering field.

In the resent years, the research of basic mechanical properties of RPC was widely developed at home and abroad, but the investigation on the axial tensile test of RPC was still deficiency. It was believed that the test methods of tensile strength include axial tensile test, splitting tensile test and flexural tensile test. Among these three methods, the former was considered to be the best one with less positioning error in terms of theory and the most difficult one in practice[3]. In this test, a self-designed axial tensile test equipment was developed and axial tensile test of RPC (the steel fiber content by volume $V_{\mathrm{f}}=0 \%, 1 \%, 2 \%$ ) was completed through Universal Testing Machine. The flexural tensile test and splitting tensile test were also developed which made it reality to compare the results of three tests.

\section{Experiment}

Materials. The mixture ratio of RPC in the test is shown in Table 1, where $V_{\mathrm{f}}$ represents the steel fiber content by volume.

Table 1 Mixture ratio of RPC

\begin{tabular}{ccccccc}
\hline$V_{\mathrm{f}}$ & $\begin{array}{c}\text { Cement } \\
{\left[\mathrm{kg} / \mathrm{m}^{3}\right]}\end{array}$ & $\begin{array}{c}\text { Silica fume } \\
{\left[\mathrm{kg} / \mathrm{m}^{3}\right]}\end{array}$ & $\begin{array}{c}\text { Quartz sand } \\
{\left[\mathrm{kg} / \mathrm{m}^{3}\right]}\end{array}$ & $\begin{array}{c}\text { Steel fiber } \\
{\left[\mathrm{kg} / \mathrm{m}^{3}\right]}\end{array}$ & $\begin{array}{c}\text { Water } \\
{\left[\mathrm{kg} / \mathrm{m}^{3}\right]}\end{array}$ & $\begin{array}{c}\text { Water-reducer } \\
{\left[\mathrm{kg} / \mathrm{m}^{3}\right]}\end{array}$ \\
\hline $0 \%$ & 706 & 160 & 1255 & 0 & 122 & 69 \\
$1 \%$ & 706 & 160 & 1255 & 80 & 122 & 69 \\
$2 \%$. & 706 & 160 & 1255 & 160 & 122 & 69 \\
\hline
\end{tabular}

Experimental Design. The specimen of RPC axial tensile test was designed as a dumbbell-shape in 
order to solve the stress concentration problem (Fig.1). The axial tensile test was finished through Universal Testing Machine with a self-designed steel test equipment (Fig.2). This equipment was made up of two high quality carbon steel clamps with ball-hinge. RPC specimens could be installed in the clamps when direct tension was applied. The test result indicates that the complete tensile stress-strain curve of RPC with $V_{\mathrm{f}}=1 \%, 2 \%$ could be obtained use this method [4].
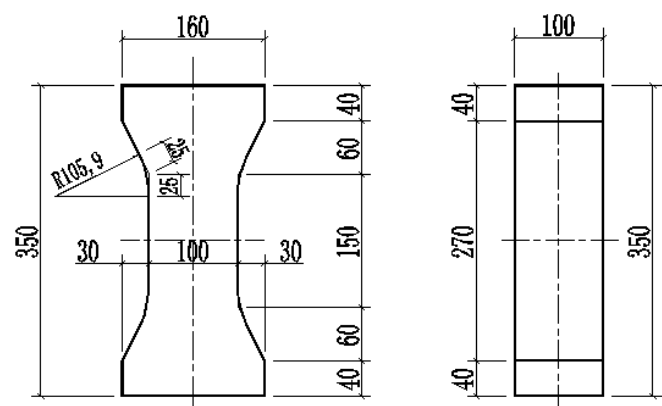

Fig. 1 Dumbbell-shaped specimen (unit: $\mathrm{mm}$ )

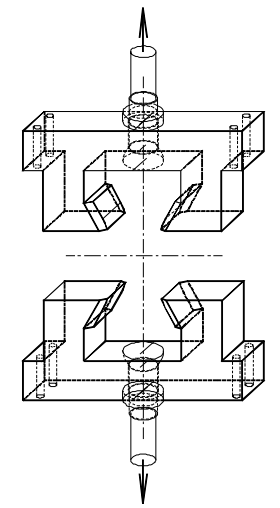

Fig.2 Constructional drawing of clamping fixture

The general situations of axial tensile test, splitting tensile test and flexural tensile test are shown in Fig.3. The specimen of splitting tensile test is a cube of $100 \mathrm{~mm}$ side length. The flexural tensile test specimen is a $100 \times 100 \times 400 \mathrm{~mm}$ cuboids. All the specimens were cast in steel matrix which was designed specially for the test. Then the specimens were steam-cured at temperature of $75{ }^{\circ} \mathrm{C}$ for 72 hours.

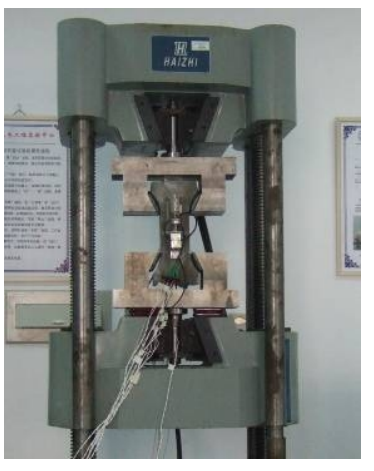

(a) axial tensile test

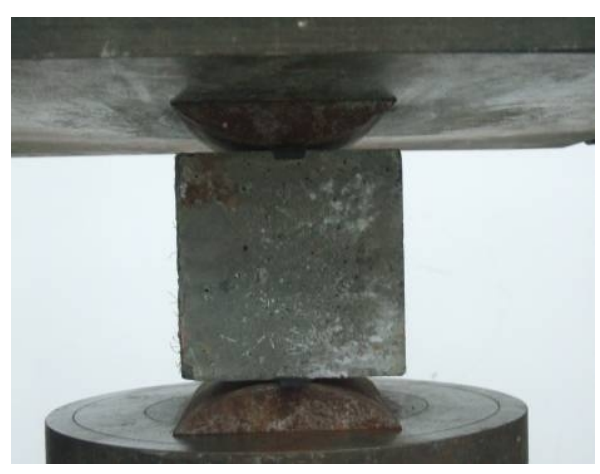

(b) splitting tensile test

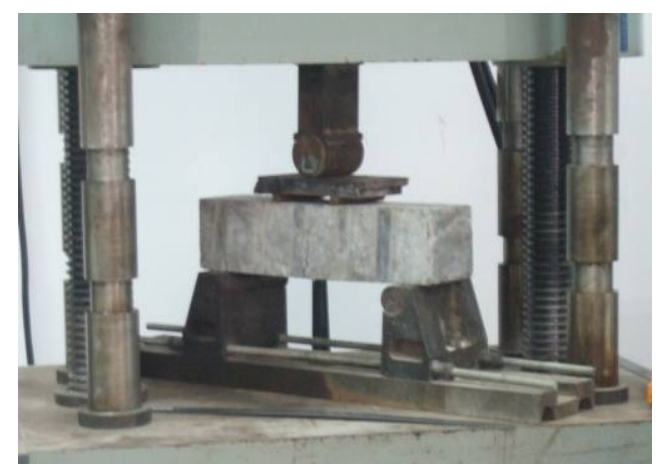

(c) flexural tensile test

Fig.3 Tensile strength test specimens of RPC

Because axial tensile test is difficult in practice, the specimen number of each group was 4 . Meanwhile there are 3 specimens in splitting tensile test and flexural tensile test respectively.

\section{Results and Discussion}

Experimental phenomena. The typical tensile failure of three tests is shown in Fig.2, Fig.3 and Fig.4. It could be observed that when $V_{\mathrm{f}}=0 \%$, the specimen was very brittle and fractured in two by increasing of the load. While with steel fiber reinforced, that is when $V_{\mathrm{f}}=1 \%, 2 \%$, the specimen creaked but was still a whole when destruction was happen. The phenomena indicated that with the volume fraction of steel fiber increasing, the tensile failure mode of RPC turned from brittleness to toughness. 


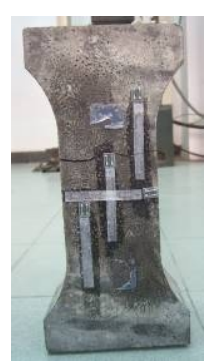

(a) $V_{\mathrm{f}}=0 \%$

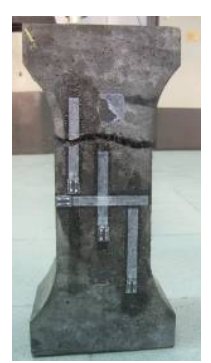

(b) $V_{\mathrm{f}}=1 \%$

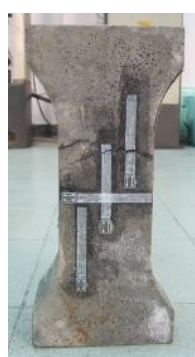

(c) $V_{\mathrm{f}}=2 \%$

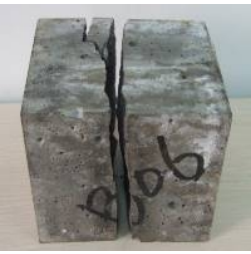

(a) $V_{\mathrm{f}}=0 \%$

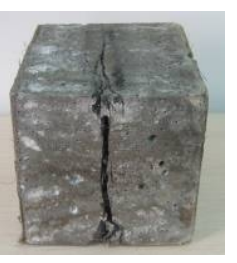

(b) $V_{\mathrm{f}}=1 \%$

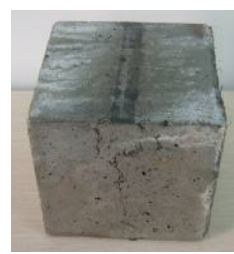

(c) $V_{\mathrm{f}}=2 \%$

Fig.2 Typical axial tensile failure mode of RPC

Fig.3 Typical splitting tensile failure mode of RPC

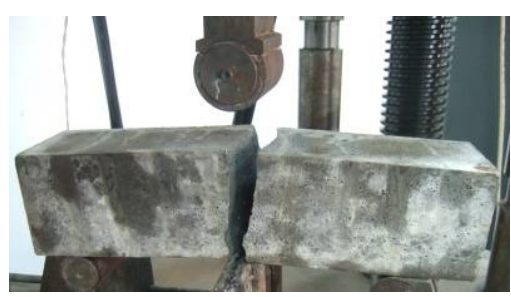

(a) $V_{\mathrm{f}}=0 \%$

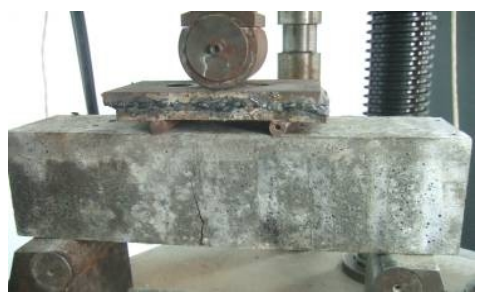

(b) $V_{\mathrm{f}}=1 \%$

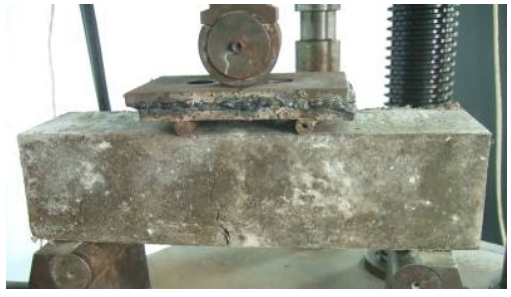

(c) $V_{\mathrm{f}}=2 \%$

Fig.4 Typical flexural failure mode of RPC

Stress-strain curve. The tensile stress-strain curves of RPC obtained in the axial tensile tests are shown in Fig. 5. It can be seen that the curve interrupted on the peak point similar as normal concrete when $V_{\mathrm{f}}=0 \%$. When the steel fiber content by volume $V_{\mathrm{f}}$ increased, the curve decreased slowly after the maximum load. The descending portion of the curve of $V_{\mathrm{f}}=2 \%$ was more flater than $V_{\mathrm{f}}=1 \%$ because there is more steel fiber absorbing energy in the specimen.

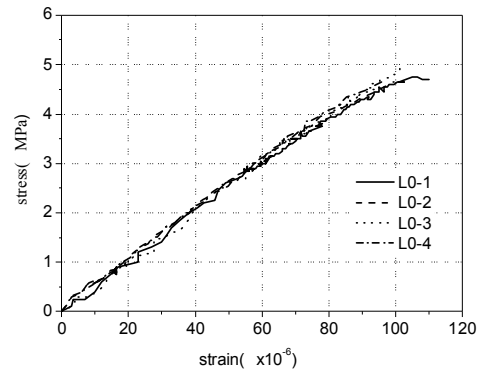

(a) $V_{\mathrm{f}}=0 \%$

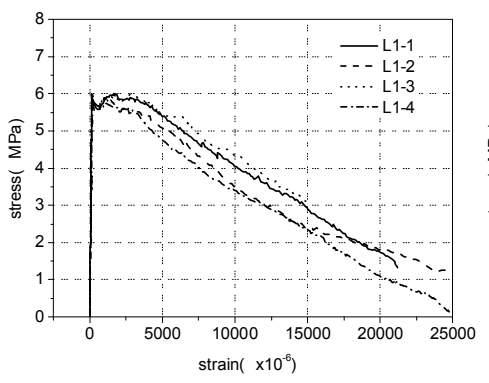

(b) $V_{\mathrm{f}}=1 \%$

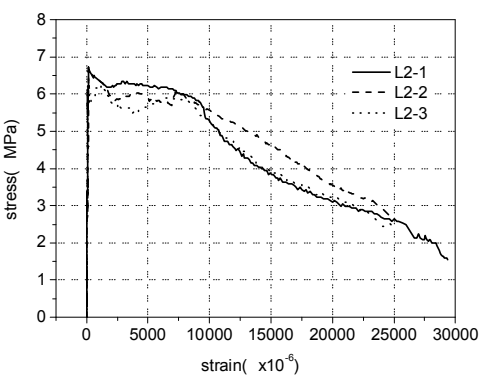

(c) $V_{\mathrm{f}}=2 \%$

Fig.5 axial tensile stress-strain curve of RPC

Main Test Results. Table 2 listed the main test results of each tensile test. Where $f_{\mathrm{t}}$ represents axial tensile strength, $f_{\mathrm{t}, \mathrm{s}}$ represents splitting tensile strength, $f_{\mathrm{t}, \mathrm{f}}$ represents flexural tensile strength. Because one specimen in the axial tensile test of $V_{\mathrm{f}}=2 \%$ was failure out of gauge length in the test, there are only three cluster of data. 
Table 2 Results of RPC's tensile test

\begin{tabular}{ccccc}
\hline$V_{\mathrm{f}}$ & Specimen & $f_{\mathrm{t}}(\mathrm{MPa})$ & $f_{\mathrm{t}, \mathrm{s}}(\mathrm{MPa})$ & $f_{\mathrm{t}, \mathrm{f}}(\mathrm{MPa})$ \\
\hline & 1 & 4.75 & 7.16 & 13.51 \\
$0 \%$ & 2 & 4.66 & 8.05 & 16.12 \\
\cline { 2 - 5 } & 3 & 4.92 & 7.52 & 12.94 \\
& 4 & 4.67 & & \\
\hline & 1 & 5.93 & 9.54 & 15.92 \\
$1 \%$ & 2 & 5.98 & 9.08 & 15.46 \\
& 3 & 5.85 & 9.77 & 15.20 \\
& 4 & 5.99 & & \\
\hline & 1 & 6.88 & 15.2 & 19.52 \\
& 2 & 6.74 & 13.6 & 20.61 \\
& 3 & 6.69 & 13.5 & 21.43 \\
\hline
\end{tabular}

Table 3 Comparison of average tensile strength value

\begin{tabular}{cccccc}
\hline$V_{\mathrm{f}}$ & $f_{\mathrm{t}}(\mathrm{MPa})$ & $f_{\mathrm{t}, \mathrm{s}}(\mathrm{MPa})$ & $f_{\mathrm{t}, \mathrm{f}}(\mathrm{MPa})$ & $\frac{f_{\mathrm{t}}}{f_{\mathrm{t}, \mathrm{s}}}$ & $\frac{f_{\mathrm{t}}}{f_{\mathrm{t}, \mathrm{f}}}$ \\
\hline $0 \%$ & 4.75 & 7.58 & 13.24 & 0.63 & 0.36 \\
$1 \%$ & 5.94 & 9.46 & 15.53 & 0.63 & 0.38 \\
$2 \%$ & 6.77 & 14.1 & 20.52 & 0.48 & 0.33 \\
\hline
\end{tabular}

\section{Summary}

Table 3 indicated that the ratio of axial tensile strength and splitting tensile strength of RPC is descending as the steel fiber volumetric ratio increasing, but the ratio of axial tensile strength and flexural tensile strength is almost stabilized. The results could be used to estimate the direct tensile strength through the flexural tensile test.

\section{Acknowledgements}

This work was financially supported by the Promotive research fund for excellent young and middle-aged scientists of Shandong Province (SBS1208) and the Jinan University Dr. Funds (XBS1040).

\section{References}

[1] P. Richard, Marcel Cheyrezy: Composition of Reactive Powder Concretes. J. Cem. Concr. Res., vol. 7 (1995), p. 1501

[2] V. Matte, M. Moranville, F. Adenot: Simulated Microstructure and Transport Properties of Ultra-high Performance Cement-based Materials. J. Cem. Concr. Res., vol. 12 (2000), p. 1947 
[3] KANG S T, KIM J K. The relation between fiber orientation and tensile behavior in an ultra high performance fiber reinforced cementitious composites [J]. Cement and Concrete Research, 2011, 41(10)1001-1014

[4] YUAN Haiyan. Theoretical analysis and experimental research on tensile performance of reinforced reactive powder concrete [D]. Beijing: Beijing Jiaotong University, 2009. 